\title{
Burden of Renal Events Associated with Nonsteroidal Anti-inflammatory Drugs in Patients with Osteoarthritis and Chronic Low Back Pain: A Retrospective Database Study
}

\author{
Takayuki Katsuno $\cdot$ Kanae Togo (D) - Nozomi Ebata $\cdot$ Koichi Fujii · \\ Naohiro Yonemoto · Lucy Abraham · Shogo Kikuchi
}

Received: November 6, 2020 / Accepted: December 22, 2020 / Published online: January 13, 2021

(C) The Author(s) 2021

\begin{abstract}
Introduction: Nonsteroidal anti-inflammatory drugs (NSAIDs) have long-term benefits but are limited by side effects. We assessed the health and economic burden of renal events associated with NSAID use in patients with osteoarthritis (OA) and/or chronic low back pain (CLBP).

Methods: This retrospective, large-scale, medical claims database study of Japanese patients receiving NSAIDs for OA and/or CLBP between 2009 and 2018 assessed the incidence of renal events and effect of treatment duration, mode of administration, and usage consistency of NSAIDs.

Results: Of 180,371 patients, NSAIDs were prescribed as first-line analgesics in $89.3 \%$.
\end{abstract}

Supplementary Information The online version contains supplementary material available at https:// doi.org/10.1007/s40122-020-00233-w.

T. Katsuno

Department of Nephrology and Rheumatology,

Aichi Medical University, Aichi, Japan

K. Togo $(\bowtie) \cdot$ N. Ebata $\cdot$ K. Fujii $\cdot$ N. Yonemoto

Pfizer Japan Inc., Tokyo, Japan

e-mail: kanae.togo@pfizer.com

L. Abraham

Pfizer Ltd., Surrey, UK

S. Kikuchi

Department of Public Health, Aichi Medical

University School of Medicine, Aichi, Japan
Incidence per 10,000 person-years (95\% confidence interval $[\mathrm{CI}]$ ) for renal events was 23.46 (21.84-25.08) and for progression of chronic kidney disease (CKD) was 267.12 (189.93-344.32). Longer treatment duration $(>1$ to $\leq 3$ years, risk ratio [RR] $1.32,95 \% \mathrm{CI}$ $1.12-1.54 ; \quad P=0.0007 ;>3$ to $\leq 5$ years, $R R$ : $1.38,95 \%$ CI $1.04-1.84 ; P=0.0254$ vs. $<1$ year) and consistent use (RR: $1.24,95 \%$ CI 0.99-1.55; $P=0.0595)$ increased the risk of renal events but the latter did not reach statistical significance. The risk was similar in patients using patch/oral NSAIDs and high in elderly patients and in those with diabetes, hypertension, and other cardiovascular disease. Following a renal event, median 1-year cost of drug treatment was \$27.90; hospitalization, \$1779.40; and dialysis, $\$ 33,018.40$.

Conclusions: Risk of renal events significantly increased with prolonged and consistent NSAID use (irrespective of mode of administration), with age, and in patients with certain comorbidities. Careful NSAID use is recommended in patients with CKD and those at high risk for CKD.

\section{PLAIN LANGUAGE SUMMARY}

Nonsteroidal anti-inflammatory drugs (NSAIDs) are commonly used in patients with osteoarthritis (OA) and/or chronic low back 
pain (CLBP) for pain relief but their use is limited by side effects. These side effects may include abdominal, heart, and kidney problems. This article presents the results from a large claims database study in Japan that assessed the incidence of renal events and the associated healthcare cost. Impact of NSAIDs treatment duration, mode of administration, and usage consistency on the risk of developing renal events was evaluated. Results showed high incidence of renal events and progression of chronic kidney disease. Longer treatment duration and consistent use increased the risk of developing renal events. The risk was similar in patients using patch/oral NSAIDs and high in elderly patients and those with diabetes, hypertension, and other heart diseases. The estimated cost of drug treatment, hospitalization, and dialysis was also high. The author of the study would recommend NSAIDs to be used carefully in patients at risk for (or with) chronic kidney disease.

Keywords: Acute kidney injury; Chronic kidney disease; Chronic low back pain; Nonsteroidal anti-inflammatory drugs; Osteoarthritis; Renal events

\section{Key Summary Points}

Why carry out this study?

Patients with osteoarthritis (OA) and/or chronic low back pain (CLBP) require long-term nonsteroidal anti-inflammatory drugs (NSAIDs) use. However, the side effects of long-term NSAIDs use limits its benefits in these patients.

Additionally, the data concerning the risk of renal events and the associated cost of renal events with long-term NSAID use in terms of treatment duration, usage consistency, and the mode of administration in these patients are limited.
We aimed to assess the health and economic burden of renal events associated with NSAID use in patients with OA and/or CLBP.

\section{What was learned from the study?}

This retrospective database study shows that prolonged and consistent NSAID use increases the risk of renal events.

Elderly patients and patients with diabetes, hypertension, and other cardiovascular disease are at increased risk of developing renal events.

\section{DIGITAL FEATURES}

This article is published with digital features, including a summary slide and a plain language summary, to facilitate understanding of the article. To view digital features for this article go to https://doi.org/10.6084/m9.figshare.13469 589.

\section{INTRODUCTION}

Nonsteroidal anti-inflammatory drugs (NSAIDs) are commonly used analgesic agents for treating pain associated with osteoarthritis (OA) and chronic low back pain (CLBP) [1, 2]. In Japan, $\sim 25.3$ million people aged $>40$ years have $\mathrm{OA}$, and the prevalence of CLBP is $\sim 15.4 \%$ in people aged $>50$ years $[3,4]$. As the elderly population is expected to rise in Japan, one would also expect to see an increase in the prevalence of patients with OA and CLBP. Currently, NSAID formulations, including oral pills and patches, are widely used to treat patients with OA and CLBP. Transdermal NSAID patches have demonstrated a superior safety profile over oral NSAIDs, and are recommended as first-line treatment for knee [5] and hip OA by the Osteoarthritis Research Society International (OARSI) guidelines [6]. In Japan, NSAIDs are also the commonly recommended and prescribed analgesics for CLBP [7]. 
NSAIDs exert anti-inflammatory, analgesic, and antipyretic effects by inhibiting cyclooxygenases (COX-1 and COX-2) and this consequently suppresses prostaglandin and thromboxane synthesis [8]. Prostaglandins play a crucial role in the regulation of renin release, electrolyte balance, and vascular tone [9]. Thus, patients using NSAIDs are susceptible to renal adverse events such as reduced glomerular filtration rate, acute kidney injury (AKI), renal papillary necrosis, nephrotic syndrome, acute interstitial nephritis (mainly due to hypersensitivity reaction), and chronic kidney disease (CKD), in addition to fluid and electrolyte retention [10]. Between $1 \%$ and $5 \%$ of NSAID users develop renal adverse effects [11]. Evidence indicates an approximately two-tothreefold increase in the risk of AKI in patients treated with NSAIDs, and this risk is reported to further increase in older adults with pre-existing $\mathrm{CKD}$ and in those using high-dose or longer half-life NSAIDs [12-18]. Progression of CKD can trigger the need for dialysis, the medical cost of which is a critical problem in Japan. There are approximately 320,000 patients receiving dialysis in Japan as of 2017, and the annual medical costs for dialysis are estimated at 1.6 trillion yen [19]. Japan has the most rapidly aging elderly population in the world; consequently, the population on dialysis is also growing.

An association between NSAID use and occurrence of renal events has been demonstrated in numerous large-scale, real-world database studies [16, 20-24]. However, these studies did not assess the impact of duration of NSAID use on the risk of renal events, which is particularly important for patients with OA and CLBP as these conditions usually require longterm treatment. Continuous or intermittent use as identified by prescription re-fill is also likely to affect the risk of renal events that has not been accounted for in previous studies. Although patch NSAIDs are considered safe, the risk of developing renal events in patients using a patch compared to oral NSAIDs when used for longer duration has not been evaluated so far. In addition, data concerning the cost of renal events associated with long-term use of NSAIDs remain scarce. To address this knowledge gap, we conducted a large database study evaluating the safety profile of NSAIDs in employed patients with CLBP and/or OA using data from the Japan Medical Data Center Co, Ltd (now JMDC Inc.). The study aimed to assess NSAID treatment characteristics that could increase the risk of renal events and identify patients who are at high risk of developing renal events. We also report the incidence of progression of CKD in a subgroup of patients who had renal comorbidities at baseline.

\section{METHODS}

\section{Study Design and Population}

This was a retrospective database analysis using anonymized claims data from the JMDC database. It is the largest claims database commercially available in Japan, and contains all claims across multiple medical institutions and can track patients who have changed institutions. It contains claims data from health insurance associations for company employees and their family members. Japan has a universal healthcare system, and the National Health Insurance covers people $\geq 75$ years old and the membership to the original health insurance society is terminated upon reaching the age of 75 years, so JMDC does not cover claims of patients who are $\geq 75$ years old.

The inclusion criteria were patients aged $\geq 18$ years at index date with an initial diagnosis of OA or CLBP (per World Health Organization International Classification of Diseases, 10th revision, ICD-10) who visited healthcare facilities between 2009 and 2018 . The index date was defined as the date when the first prescription of analgesic was given after the initial diagnosis of OA or CLBP. Patients taking $\geq 2$ prescriptions of the same or different analgesics with $\geq 1$-month gap after initial OA/ CLBP diagnosis were included. These patients were not required to have any prescriptions for analgesics in the baseline period (6 months from the index date). Patients were excluded if they had malignancy (ICD10 codes: C00-C97, 
D00-D09) after the initial diagnosis of OA or CLBP. The ICD-10 diagnosis of OA was defined by the codes M16 and M1, and CLBP was confirmed by at least two ICD-10 low back pain diagnoses (M40, M41, M43, M45-M48, and M50-M54). Diseases excluded from chronic low back pain are included in Table S1 (see in the electronic supplementary material).

\section{Exposure}

The exposure period of NSAIDs ended on the day when the first event occurred in patients with a renal event. The NSAID treatment variables were duration of treatment, mode of administration (oral drugs, patch, other transdermal drugs), and consistency of NSAID use. Categories of treatment duration were $>0$ to 1 year, $>1$ to $\leq 3$ years, $>3$ to $\leq 5$ years, and $>5$ years. Consistent NSAID use was defined as a percentage of the number of supply days in a total treatment duration of $\geq 70 \%$, and intermittent use was identified as a percentage of the number of supply days in a total treatment duration of $<70 \%$.

\section{Study Outcomes}

Incidence of renal disease (renal events) and progression of CKD, and their medical costs were assessed. Renal events included acute/ chronic tubulointerstitial nephritis, NSAID nephropathy, drug-induced renal disease, AKI, CKD, and end-stage renal failure (see Table S2 in the electronic supplementary material). Although the disease names of interstitial nephritis and drug-induced renal disease should be the events related to NSAID use, broad terms of acute/chronic renal failure or kidney disease are commonly used in medical practice; thus, 'renal events' included these conditions in patients who did not have them at baseline. Progression of CKD was defined as initiation of dialysis after treatment with NSAIDs in patients with comorbidity of renal disease without dialysis at baseline.

Costs of drug treatment, dialysis, and hospitalization constituted healthcare resource utilization data. The total costs of drug treatment and hospitalization were calculated for 12 months after onset of the event. The basic direct cost of dialysis started when a patient underwent dialysis for 12 months after NSAID treatment.

\section{Statistical Analysis}

All analyses were done using SAS version 9.4 (SAS Institute, Cary, NC, USA). Continuous variables are summarized using descriptive statistics or frequencies for dichotomous and polychotomous variables of categorical data. An alpha level of $<0.05$ was considered statistically significant. The crude incidence (per 10,000 person-years) of renal events with its $95 \%$ confidence interval (CI) was calculated. An overdispersed Poisson regression model using the SAS GLIMMIX procedure was used to identify factors affecting incidence of renal events with covariates of age at index date, gender, baseline comorbidities of diabetes mellitus, gastrointestinal, and cardiovascular (CV) disease. However, model analysis was not performed for the progression of CKD because of the anticipated small sample size owing to a low percentage of patients with renal disease at baseline.

\section{Ethics Statement}

As this study involved anonymized structured data, which according to applicable legal requirements did not contain data subject to privacy laws, obtaining informed consent from patients was not required. As Japanese Ethical Guidelines [25] for 'Medical and Health Research Involving Human Subjects' do not apply to studies that use anonymized secondary data, this study was not reviewed by an institutional review board/research ethics committee.

\section{RESULTS}

\section{Patient Disposition and NSAID Treatment}

Of 628,488 patients diagnosed with OA or CLBP who used analgesics at least once in the JMDC 


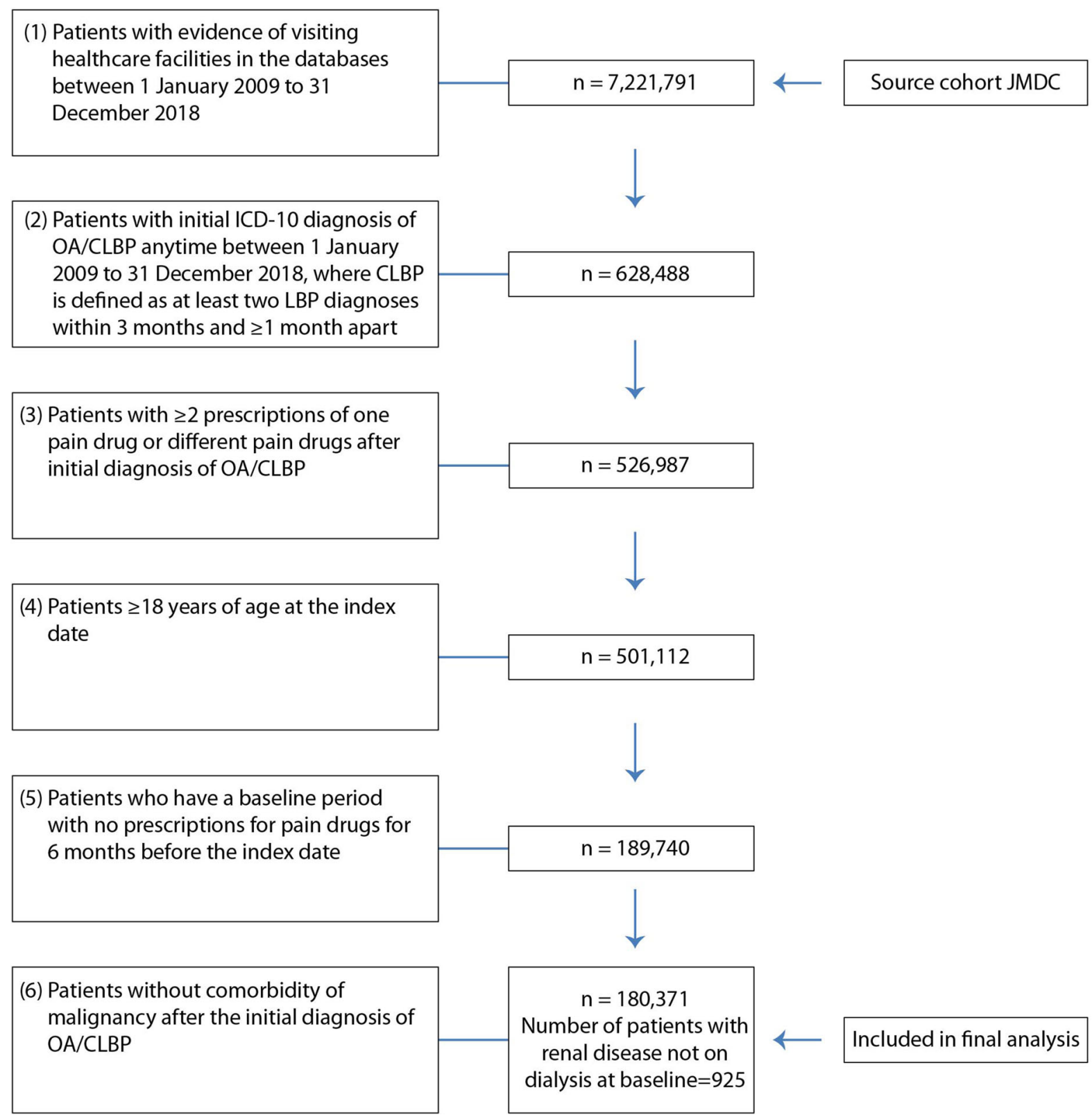

Fig. 1 Patient disposition. $C L B P$ chronic low back pain, $I C D-10$ International Classification of Disease-10, JMDC Japan Medical Data Center, $L B P$ low back pain, $O A$ osteoarthritis

database, 180,371 met the eligibility criteria and were included in this analysis (Fig. 1). A total of $32.9 \%$ patients had OA, 53.8\% had CLBP, and $13.4 \%$ had both OA and CLBP. Diabetes was reported in $11.8 \%$ patients, and hypertension in $21.9 \%$. Renal comorbidities were present in $1454(0.8 \%)$ patients (Table 1).

NSAIDs were prescribed as first-line analgesics to $161,152(89.3 \%)$ patients: oral to
90.3\%; patches to $80.4 \%$; and other transdermal drugs to $24.0 \%$ (see Table S3 in the electronic supplementary material). In a subgroup of patients with renal comorbidities at baseline $(n=1186), \quad 76.9 \%$ were administered oral NSAIDs and $85.6 \%$ received NSAIDs patches as the first-line analgesic (see Table S3 in the electronic supplementary material). A total of $83.8 \%$ and $77.5 \%$ of patients used NSAIDs for 
Table 1 Patient demographic and clinical characteristics

\begin{tabular}{|c|c|c|}
\hline Characteristics & $\begin{array}{l}\text { All patients } \\
(N=180,371)\end{array}$ & $\begin{array}{l}\text { Patients with renal } \\
\text { disease not on } \\
\text { dialysis at baseline } \\
(n=925)\end{array}$ \\
\hline $\begin{array}{l}\text { Age at index } \\
\text { date (years), } \\
\text { mean } \pm S D\end{array}$ & $49.3 \pm 11.8$ & $56.3 \pm 10.18$ \\
\hline \multicolumn{3}{|c|}{ Age categories (years), $n$ (\%) } \\
\hline 18 to $<30$ & $12,244(6.8)$ & $12(1.3)$ \\
\hline 30 to $<40$ & $24,319(13.5)$ & $49(5.3)$ \\
\hline 40 to $<50$ & $47,068(26.1)$ & $156(16.9)$ \\
\hline 50 to $<60$ & $59,447(33.0)$ & $323(34.9)$ \\
\hline 60 to $<70$ & $32,646(18.1)$ & $307(33.2)$ \\
\hline 70 to $\leq 75$ & $4647(2.6)$ & $78(8.4)$ \\
\hline $\begin{array}{l}\text { Male gender, } \\
n(\%)\end{array}$ & $92,650(51.4)$ & $615(66.5)$ \\
\hline \multicolumn{3}{|l|}{ Diagnosis, $n(\%)$} \\
\hline $\mathrm{OA}$ & $59,318(32.9)$ & $243(26.3)$ \\
\hline CLBP & $96,959(53.8)$ & $527(57.0)$ \\
\hline $\begin{array}{l}\text { Both OA and } \\
\text { CLBP }\end{array}$ & $24,094(13.4)$ & $155(16.8)$ \\
\hline \multicolumn{3}{|c|}{ Affected joints in OA patients, $n$ (\%) } \\
\hline Coxarthrosis & $11,765(14.1)$ & $47(5.1)$ \\
\hline Gonarthrosis & $71,647(85.9)$ & $286(30.9)$ \\
\hline \multicolumn{3}{|c|}{ Comorbidities, $n(\%)$} \\
\hline GI disease & $14,285(7.9)$ & $184(19.9)$ \\
\hline Renal disease & $1454(0.8)$ & NA \\
\hline $\begin{array}{l}\text { CV disease } \\
\text { (excluding } \\
\text { hypertensive } \\
\text { disease) }\end{array}$ & $24,238(13.4)$ & $420(45.4)$ \\
\hline Hypertension & $39,413(21.9)$ & $672(72.6)$ \\
\hline $\begin{array}{l}\text { Diabetes } \\
\text { mellitus }\end{array}$ & $21,240(11.8)$ & $428(46.3)$ \\
\hline
\end{tabular}

$C L B P$ chronic low back pain, $C V$ cardiovascular, $G I$ gastrointestinal, $O A$ osteoarthritis, $N A$ not applicable up to 1 year in the total study population and those who had renal comorbidities at baseline, respectively. Combination of oral and patch NSAIDs was used by $65.1 \%$ and $52.7 \%$ of patients in the whole study population and those who had renal comorbidities at baseline, respectively (see Table S4 in the electronic supplementary material).

\section{Renal Events}

The incidence rate of renal events was 23.46/ 10,000 person-years (95\% CI 21.84-25.08) in the study population. Of 806 renal events, the most common were CKD (45.2\%), chronic renal failure $(35.7 \%)$, and acute renal failure $(8.8 \%)$ (see Table S5 in the electronic supplementary material).

The event rate was higher in patients who used NSAIDs for $\geq 1$ year: $>0$ to $\leq 1$ year, 20.37 (95\% CI $18.59-22.14$ ); $>1$ to $\leq 3$ years, 30.64 (95\% CI $26.67-34.61) ;>3$ to $\leq 5$ years, 36.10 (95\% CI 26.73-45.47); and $\geq 5$ years, 29.95 (95\% CI 14.79-45.10). However, it should be noted that the number of patients who used NSAIDs for $\geq 5$ years in this study was very low (15 events/755 patients). The incidence was also higher in patients who used NSAIDs consistently compared to those who did not $(37.45$ $\left[\begin{array}{lll}95 \% & \text { CI } 30.28-44.61] & \text { vs. } 22.22\end{array}\right][95 \%$ CI 20.58-23.87]). Similarly, the risk of renal events was higher in patients who only used patch NSAIDs compared to oral NSAIDs only (32.49 $\left[\begin{array}{lll}95 \% & \text { CI } & 22.16-42.82]\end{array}\right]$ vs. $19.76 \quad[95 \%$ CI 14.88-24.64]) (Table 2). After adjusting the covariates, age, sex, and comorbidities in the multivariate analysis, the duration of treatment was a significant factor that increased the risk of developing renal events $(>1$ to $\leq 3$ years, risk ratio [RR] 1.32, 95\% CI 1.12-1.54; $P=0.0007 ;>3$ to $\leq 5$ years, RR: $1.38,95 \% \mathrm{CI}$ $1.04-1.84 ; P=0.0254$ ) while consistency of use was not statistically significant but showed a trend towards increasing the risk of developing renal events (RR: 1.24, 95\% CI 0.99-1.55; $P=0.0595$ ) (Table 3). The risk of developing renal events was similar in patients using only patch or only oral NSAIDs (RR: $0.97,95 \%$ CI $0.64-1.46 ; \quad P=0.8650)$ in the multivariate 
Table 2 Incidence of renal events stratified as per treatment duration, consistency of use, and mode of administration

\begin{tabular}{|c|c|c|c|}
\hline \multirow{2}{*}{$\begin{array}{l}\text { Treatment } \\
\text { characteristic }\end{array}$} & \multicolumn{3}{|c|}{ Renal events } \\
\hline & $\bar{N}$ & $\begin{array}{l}n \text { of } \\
\text { patients } \\
\text { with } \\
\text { event }\end{array}$ & $\begin{array}{l}\text { Incidence rate per } \\
10,000 \text { person- } \\
\text { years }(95 \% \mathrm{CI})\end{array}$ \\
\hline
\end{tabular}

Total $\quad 159,966 \quad 806 \quad 23.46(21.84-25.08)$

NSAID treatment duration, years

$$
\begin{array}{lrrrr}
>0 \text { to } \leq 1 & 134,117 & 505 & 20.37(18.59-22.14) \\
>1 \text { to } \leq 3 & 21,908 & 229 & 30.64(26.67-34.61) \\
>3 \text { to } \leq 5 & 3186 & 57 & 36.10(26.73-45.47) \\
\geq 5 & 755 & 15 & 29.95(14.79-45.10)
\end{array}
$$

Percentage of supply days during treatment period

$$
\begin{array}{llll}
<70 \% & 126,467 & 701 & 22.22(20.58-23.87) \\
\geq 70 \% & 33,499 & 105 & 37.45(30.28-44.61)
\end{array}
$$

Mode of administration

$$
\begin{array}{llll}
\text { Oral } & 21,536 & 63 & 19.76(14.88-24.64) \\
\text { Patch } & 11,096 & 38 & 32.49(22.16-42.82)
\end{array}
$$

Combination of oral and non-oral ${ }^{\mathrm{a}}$

\begin{tabular}{llll} 
Yes & 69,377 & 316 & $21.83(19.42-24.24)$ \\
No & 90,589 & 490 & $24.65(22.47-26.84)$ \\
\hline
\end{tabular}

$C I$ confidence interval, NSAID nonsteroidal anti-inflammatory drug

\begin{tabular}{|c|c|c|}
\hline Covariates & $\begin{array}{l}\text { Risk ratio }(95 \% \\
\text { CI) }\end{array}$ & $P$ value \\
\hline \multicolumn{3}{|c|}{ Age, years vs. 18 to $<30$ years } \\
\hline 30 to $<40$ & $1.03(0.59-1.80)$ & 0.9249 \\
\hline 40 to $<50$ & $2.08(1.26-3.42)$ & 0.0041 \\
\hline 50 to $<60$ & $2.96(1.81-4.83)$ & $<0.0001$ \\
\hline 60 to $<70$ & $4.10(2.49-6.74)$ & $<0.0001$ \\
\hline 70 to $\leq 80$ & $6.88(3.91-12.09)$ & $<0.0001$ \\
\hline Gender, male vs. female & $1.88(1.62-2.18)$ & $<0.0001$ \\
\hline Baseline GI & $0.92(0.64-1.32)$ & 0.6576 \\
\hline Baseline CV & $1.46(1.15-1.87)$ & 0.0022 \\
\hline Baseline hypertension & $1.63(1.26-2.10)$ & 0.0002 \\
\hline Baseline diabetes mellitus & $1.97(1.53-2.55)$ & $<0.0001$ \\
\hline \multicolumn{3}{|c|}{ Duration of treatment, years vs. $<1$ year } \\
\hline$>1$ to $\leq 3$ & $1.32(1.12-1.54)$ & 0.0007 \\
\hline$>3$ to $\leq 5$ & $1.38(1.04-1.84)$ & 0.0254 \\
\hline$\geq 5$ & $1.19(0.70-2.01)$ & 0.5298 \\
\hline $\begin{array}{l}\text { Consistent use of } \\
\text { NSAIDs, percentage of } \\
\text { supply days } \geq 70 \%\end{array}$ & $1.24(0.99-1.55)$ & 0.0595 \\
\hline vs. $<70 \%$ & & \\
\hline
\end{tabular}

a Non-oral includes topical including patch, other transdermal drugs (cream, gel, liquid, lotion, ointment), and suppository

analysis. The risk of renal events was found to significantly increase with increasing age, and the risk was threefold higher in patients aged 70-80 years compared to those who were $40-50$ years ( 40 to $<50$ years, RR: $2.08,95 \%$ CI $1.26-3.42 ; \quad P=0.0041 ; 70$ to $\leq 80$ years, RR: 6.88, 95\% CI 3.91-12.09; $P<0.0001)$. Among other comorbid conditions (hypertension and other CV diseases), diabetes was shown to increase the risk twofold (RR: 1.97, 95\% CI
Table 3 Multivariate model analysis with covariates for the renal event

Method of administration compared to oral

\begin{tabular}{lll} 
Patch & $0.97(0.64-1.46)$ & 0.8650 \\
Other $^{\mathrm{a}}$ & $0.99(0.75-1.30)$ & 0.9321 \\
Combination use & $0.88(0.76-1.02)$ & 0.0963 \\
\hline
\end{tabular}

$C I$ confidence interval, $C V$ cardiovascular, $G I$ gastrointestinal, NSAIDs nonsteroidal anti-inflammatory drugs

${ }^{a}$ Other is transdermal drugs other than patch (cream, gel, liquid, lotion, ointment) and suppository

$1.53-2.55 ; P<0.0001)$. The incidence of progression of CKD was 267.12/10,000 personyears (95\% CI 189.93-344.32) (Table 4). Compared with the whole study population, patients with renal disease at baseline were older, predominantly men, and had higher prevalence of 
Table 4 Incidence of progression of CKD in patients with renal disease not on dialysis at baseline

\begin{tabular}{|c|c|c|c|}
\hline \multirow{2}{*}{$\begin{array}{l}\text { Treatment } \\
\text { characteristic }\end{array}$} & \multicolumn{3}{|c|}{ Progression of CKD } \\
\hline & $\bar{N}$ & $\begin{array}{l}n \text { of } \\
\text { patients } \\
\text { with event }\end{array}$ & $\begin{array}{l}\text { Incidence rate per } \\
10,000 \text { person-years } \\
(95 \% \mathrm{CI})\end{array}$ \\
\hline Total & 925 & 46 & $\begin{array}{l}267.12 \\
\quad(189.93-344.32)\end{array}$ \\
\hline
\end{tabular}

NSAID treatment duration, years

$$
\begin{array}{lrrrc}
>0 \text { to } \leq 1 & 737 & 29 & 254.38 \\
& & & (161.79-346.96) \\
>1 \text { to } \leq 3 & 158 & 12 & 268.83 \\
& & & (116.73-420.93) \\
>3 \text { to } \leq 5 & 23 & 4 & 413.00(8.26-817.74) \\
\geq 5 & 7 & 1 & 257.95(0.00-763.49)
\end{array}
$$

\begin{tabular}{|c|c|c|}
\hline Yes & $\begin{array}{ll}354 & 13\end{array}$ & $\begin{array}{l}189.15 \\
\quad(86.33-291.97)\end{array}$ \\
\hline No & $571 \quad 33$ & 318.91 \\
\hline
\end{tabular}

Percentage of supply days during treatment period

$$
\begin{array}{cccc}
<70 \% & 675 & 41 & 278.28 \\
& & & (193.10-363.46) \\
\geq 70 \% & 250 & 5 & 201.05 \\
& & & (24.83-377.27)
\end{array}
$$

Mode of administration

$$
\begin{array}{llll}
\text { Oral } & 102 & 0 & \text { NC } \\
\text { Patch } & 140 & 3 & 207.57(0.00-442.45)
\end{array}
$$

Combination of oral and non-oral

(210.10-427.72)

\begin{tabular}{|c|c|c|}
\hline \multirow[t]{2}{*}{ Criteria } & \multicolumn{2}{|c|}{ Cost $(\$)$} \\
\hline & & Median (Q1-Q3) \\
\hline \multicolumn{3}{|c|}{$\begin{array}{l}\text { Patients without renal disease at baseline who developed } \\
\text { renal event }\end{array}$} \\
\hline $\begin{array}{l}\text { Cost due to } \\
\text { drug treatment } \\
\text { for } 1 \text { year }\end{array}$ & 60 & $27.90(6.80-65.50)$ \\
\hline $\begin{array}{l}\text { Total cost of } \\
\text { hospitalization } \\
\text { due to renal } \\
\text { events }\end{array}$ & 9 & $1779.40(1081.60-2857.00)$ \\
\hline \multicolumn{3}{|c|}{$\begin{array}{l}\text { Patients with renal disease at baseline who underwent } \\
\text { dialysis after treatment with NSAIDs }\end{array}$} \\
\hline $\begin{array}{l}\text { Dialysis for the } \\
\text { first month }\end{array}$ & 44 & $2347.30(1665.40-2657.60)$ \\
\hline $\begin{array}{l}\text { Dialysis for } \\
1 \text { year }\end{array}$ & 26 & $33,018.40(23,124.50-35,485.60)$ \\
\hline
\end{tabular}

Lower limit of confidence interval was truncated at zero $C I$ confidence interval, $C K D$ chronic kidney disease, $N C$ confidence interval was not computed as there was no event in patients using oral NSAIDs, NSAID nonsteroidal anti-inflammatory drug

diabetes, hypertension, and other CV disease (Table 1). The pattern of renal events and that of progression of CKD remained similar for both OA and CLBP patients (see Tables S6 and S7 in the electronic supplementary material).
Table 5 Health resource utilization due to renal events

$N S A I D$ nonsteroidal anti-inflammatory drug, $Q$ quarter

\section{Health Resource Utilization Due to Renal Events}

The median (interquartile range [IQR]) cost of 1 year of drug treatment following a renal event was $\$ 27.90$ (6.80-65.50). The median cost of hospitalization was $\$ 1779.40$ (1081.60-2857.00) (Table 5). The median (IQR) length of hospital stay was 10 days (8-13). The cost of dialysis for the first month was $\$ 2347.30$ (1665.40-2657.60) and for 1 year was $\$ 33,018.40 \quad(23,124.50-35,485.60)$. The cost estimates remained similar for both $\mathrm{OA}$ and CLBP patients (see Table S8 in the electronic supplementary material).

\section{DISCUSSION}

This contemporary large-scale database study reports, for the first time, the incidence and economic burden of NSAID-associated renal events using claims data of medical insurance 
beneficiaries employed by middle-to-large size companies in Japan. The incidence rate of renal events was 23.46 per 10,000 person-years $(95 \%$ CI 21.84-25.08) that increased with longer duration of treatment. As expected, the incidence of renal events was higher in a subgroup of patients with renal comorbidities compared to the total study population.

The prevalence of CKD based on the glomerular filtration rates in Japanese adult population was estimated to be $13 \%$ [26]. As no studies have reported NSAID-associated renal events in the general Japanese population or in disease subgroups to date, our study may fill this gap and could contribute to optimal management of OA and CLBP patients in Japan. Although there are no data available even from outside of Japan to compare with the incidence rate in our study, the annual incidence of CKD was 13 per 10,000 for men and seven per 10,000 for women in a cohort study of the French general population [27]. The community-acquired incidence of AKI associated with NSAIDs was reported to be 68 per 10,000 person-years among 78,379 patients using renin-angiotensin system inhibitors and/or diuretics in the United Kingdom [28]. Our study results, showing an increased risk of renal events with longer duration of treatment, is consistent with previous studies that have shown that long-term use of NSAIDs is associated with unfavorable renal outcomes $[20,21]$. This finding is quite important given the current guidelines recommend against long-term NSAID-use [5, 7]. The reasons for their long-term use in Japan may be due to the preference of patch NSAIDs over other forms of NSAIDs and that the upper limit to the number of patches that can prescribed at a time is regulated by the Japanese government. NSAIDs may decrease renal blood flow, induce precipitation of crystals leading to tubular obstruction, exert direct cytotoxicity, and activate cell-mediated immune injury mechanisms, resulting in AKI [29]. Interstitial nephritis is another common pathological change caused by NSAIDs that may require renal biopsy and specialist management with immunosuppressants, and may progress to CKD [29].

In this study, elderly patients and patients with diabetes, hypertension, and other $\mathrm{CV}$ disease were at high risk of developing renal events, which is in agreement with previous reports [30, 31]. In these patients, the autoregulation of renal blood flow is impaired, and consistent long-term use of NSAIDs may aggravate the reduction in blood flow [32]. Further, as hypertension and heart failure are often prevalent in elderly patients with chronic pain, the co-prescription of angiotensin receptor blockers, angiotensin-converting enzyme inhibitors, or diuretics with NSAIDs is common; this has the potential to compromise renal blood flow and contribute to worsening of renal ischemia $[33,34]$. Interestingly, the risk of renal events was similar in patients using oral or patch NSAIDs in our study indicating that switching patients from oral to patch NSAIDs in these high-risk patients would not offer any additional benefits in reducing risk of renal events. Although systemic exposure of topical NSAIDs is reported to be lower than that of the oral NSAIDs, repeated use or a high dose of topical NSAIDs may increase systemic concentration approaching that of oral NSAIDs.

Importantly, studies show that numbers of adverse events, however low, are observed even in patients using topical NSAIDs [35, 36]. Moreover, data comparing renal adverse effects between topical and systemic NSAIDs when they are used consistently over the long term are lacking. Therefore, appropriate assessment of medical history regarding comorbid hypertension or heart failure should be performed if NSAIDs are required to relieve pain in patients with CKD or who are at higher risk of developing CKD. NSAIDs should be used for a limited period with careful monitoring of renal function, and if renal dysfunction is observed and the patient still needs pain relief, switching to an alternative analgesic should be considered [37].

Those patients with abnormal renal function at baseline have a three-to-fourfold increased risk of deterioration in renal function compared to those with normal renal function [38]. Although the severity of renal disease at baseline was unknown, the incidence of progression of CKD found in this study $(267.12 / 10,000$ person-years) was remarkably high compared to the prevalence rate for dialysis reported for the 
general population $(26.9 / 10,000$ persons $)$ in Japan [39]. The higher incidence rate may be due to a high-risk population. Patients who had renal disease at baseline were mainly men and had a higher prevalence of comorbidities, such as diabetes, hypertension, and other CV disease, and the risk was found to increase with increasing age. Despite the recommendation against the use of NSAIDs in CKD [40], several studies report that a significant percentage of patients still receive them. Approximately $15.4 \%$ of CKD patients were prescribed traditional NSAIDs or COX-2 inhibitors in the United States, $11.1 \%$ in the United Kingdom, and $15.9 \%$ in Australia [41-43]. Better quantification of risks is recommended in people with CKD when NSAIDs are used [44]. In this context, for patients at high risk of developing renal events, analgesics that do not influence renal COX mechanisms and are potent enough to relieve the pain associated with OA and CLBP may be of potential clinical relevance.

The monthly cost of dialysis was $\$ 2347.30$ in our study. Although the dialysis cost in this study included only the direct cost and did not include the cost of medications, laboratory tests, diagnostic imaging, and management of dialysis-associated adverse events, the annual cost was considerable $(\$ 33,018.40)$. Takura et al. reported the annual direct medical cost including examination, consultation, and rehabilitation was $\$ 45,200$ [45]. Moreover, the burden of dialysis is increasing worldwide [46] and it is also associated with a high degree of perceived caregiver burden [47].

There are some implicit database-related limitations of the study. In the absence of medical chart information, the severity of disease, dose of NSAIDs, and actual drug use could not be assessed. Since the database does not include information, which could confirm the diagnosis of renal events, we relied upon the physician's opinion/diagnosis. Data for patients $>65$ years were limited and no data were available for patients $>75$ years. Thus, we cannot generalize the study results to the entire Japanese population but they can be generalized for those between the ages 18 and 75 years. Patients who withdrew from the JMDC database could not be identified. There may be unmeasured confounding factors that limit interpretation of the model analysis. The study allows estimating the incidence of renal events but does not allow establishing causality with NSAIDs directly. The main strength of the study is that it provides robust real-world evidence from a large administrative claims database. The JMDC database allows an accurate estimation of the incidence because it issues a unique identifier to insured individuals enabling tracking of patient movement and treatment across medical institutions until they withdraw from their health insurance provider.

\section{CONCLUSIONS}

The risk of developing renal events was higher in older patients and in patients with diabetes, hypertension, and other CV diseases. Results showed that the risk increased with prolonged and consistent use of NSAIDs. The risk of renal events remained similar in patients using a patch or oral NSAIDs. Careful use of NSAIDs is recommended in patients with CKD and those who are at high risk for CKD.

\section{ACKNOWLEDGEMENTS}

Funding. The study and the journal's Rapid Service Fee were sponsored by Pfizer Japan Inc.

Medical Writing and/or Editorial Assistance. The study was sponsored by Pfizer Japan Inc. Editorial/medical writing support was provided by MedPro Clinical Research, supported by CBCC Global Research, and was funded by Pfizer Japan Inc. Data analytics support was provided by the Institute of Japanese Union of Scientists \& Engineers, who were paid contractors to Pfizer Japan Inc. in the development of this manuscript.

Authorship. All named authors meet the International Committee of Medical Journal Editors (ICMJE) criteria for authorship for this article, take responsibility for the integrity of 
the work as a whole, and have given their approval for this version to be published.

Authorship Contributions. All authors contributed to the concept and design of the study, analysis and interpretation of data, drafting/revising the manuscript for important intellectual content, and approval of the final version to be published. KT and NE were also involved in the acquisition of data.

Disclosures. Kanae Togo, Nozomi Ebata, Koichi Fujii, and Naohiro Yonemoto are employees of Pfizer Japan Inc., and shareholders of Pfizer Inc. Lucy Abraham is an employee and shareholder of Pfizer Ltd. Shogo Kikuchi and Takayuki Katsuno do not have any conflicts of interest to declare.

Compliance with Ethics Guidelines. As this study involved anonymized structured data, which according to applicable legal requirements did not contain data subject to privacy laws, obtaining informed consent from the patients was not required. This study was conducted in accordance with legal and regulatory requirements according to the guidelines for Good Pharmacoepidemiology Practices issued by the International Society for Pharmacoepidemiology, Good Practices for Outcomes Research (International Society for Pharmacoeconomics and Outcomes Research, ISPOR).

Data Availability. The datasets generated during and/or analyzed during the current study are not publicly available as all the rights for database ownership are reserved with the JMDC Inc. However, Pfizer Inc. has a contract with JMDC to use this database and publish the results.

Open Access. This article is licensed under a Creative Commons Attribution-NonCommercial 4.0 International License, which permits any non-commercial use, sharing, adaptation, distribution and reproduction in any medium or format, as long as you give appropriate credit to the original author(s) and the source, provide a link to the Creative Commons licence, and indicate if changes were made. The images or other third party material in this article are included in the article's Creative Commons licence, unless indicated otherwise in a credit line to the material. If material is not included in the article's Creative Commons licence and your intended use is not permitted by statutory regulation or exceeds the permitted use, you will need to obtain permission directly from the copyright holder. To view a copy of this licence, visit http://creativecommons.org/licenses/by$\mathrm{nc} / 4.0 /$.

\section{REFERENCES}

1. Mills S, Torrance N, Smith BH. Identification and management of chronic pain in primary care: a review. Curr Psychiatry Rep. 2016;18(2):22.

2. Akazawa M, Mimura W, Togo K, et al. Patterns of drug treatment in patients with osteoarthritis and chronic low back pain in Japan: a retrospective database study. J Pain Res. 2019;12:1631-48.

3. Iizuka Y, Iizuka H, Mieda T, et al. Prevalence of chronic nonspecific low back pain and its associated factors among middle-aged and elderly people: an analysis based on data from a musculoskeletal examination in Japan. Asian Spine J. 2017;11(6): 989-97.

4. Yoshimura N. Epidemiology of osteoarthritis in Japan: the ROAD study. Clin Calcium. 2011;21(6): 821-5.

5. Zhang W, Moskowitz RW, Nuki G, et al. OARSI recommendations for the management of hip and knee osteoarthritis, part II: OARSI evidence-based, expert consensus guidelines. Osteoarthr Cartil. 2008;16(2):137-62.

6. Bannuru RR, Osani M, Vaysbrot E, et al. OARSI guidelines for the non-surgical management of knee, hip, and polyarticular osteoarthritis. Osteoarthr Cartil. 2019;27(11):1578-89.

7. The Japanese Orthopaedic A. Clinical practice guideline on the management of low back pain. 2nd ed. Tokyo: Nankodo Co., Ltd.; 2019.

8. Onder G, Pellicciotti F, Gambassi G, Bernabei R. NSAID-related psychiatric adverse events. Drugs. 2004;64(23):2619-27.

9. Cheng H-F, Harris RC. Cyclooxygenases, the kidney, and hypertension. Hypertension. 2004;43(3): 525-30. 
10. Harirforoosh S, Asghar W, Jamali F. Adverse effects of nonsteroidal antiinflammatory drugs: an update of gastrointestinal, cardiovascular and renal complications. J Pharm Pharm Sci. 2013;16(5):821-47.

11. Harirforoosh S, Jamali F. Renal adverse effects of nonsteroidal anti-inflammatory drugs. Expert Opin Drug Saf. 2009;8(6):669-81.

12. Griffin MR, Yared A, Ray WA. Nonsteroidal antiinflammatory drugs and acute renal failure in elderly persons. Am J Epidemiol. 2000;151(5):488-96.

13. Winkelmayer WC, Waikar SS, Mogun H, Solomon $\mathrm{DH}$. Nonselective and cyclooxygenase-2-selective NSAIDs and acute kidney injury. Am J Med. 2008;121(12):1092-8.

14. Murray MD, Black PK, Kuzmik DD, et al. Acute and chronic effects of nonsteroidal antiinflammatory drugs on glomerular filtration rate in elderly patients. Am J Med. 1995;310(5):188-97.

15. Huerta C, Castellsague J, Varas-Lorenzo C, Rodríguez LAG. Nonsteroidal anti-inflammatory drugs and risk of ARF in the general population. Am J Kidney Dis. 2005;45(3):531-9.

16. Schneider V, Lévesque LE, Zhang B, Hutchinson T, Brophy JM. Association of selective and conventional nonsteroidal antiinflammatory drugs with acute renal failure: a population-based, nested casecontrol analysis. Am J Epidemiol. 2006;164(9): 881-9.

17. Gooch K, Culleton BF, Manns BJ, et al. NSAID use and progression of chronic kidney disease. Am J Med. 2007;120(3):280.e1-e7.

18. Nelson DA, Marks ES, Deuster PA, O'Connor FG, Kurina LM. Association of nonsteroidal anti-inflammatory drug prescriptions with kidney disease among active young and middle-aged adults. JAMA Netw Open. 2019;2(2):e187896.

19. Nakamoto $H$. The current status and future of peritoneal dialysis in Japan. In: Nakanishi T, Kuragano $\mathrm{T}$, editors. CKD-associated complications: progress in the last half century, vol. 198. Basel: Karger; 2019. p. 78-86.

20. Ingrasciotta Y, Sultana J, Giorgianni F, et al. Association of individual non-steroidal anti-inflammatory drugs and chronic kidney disease: a population-based case control study. PLOS ONE. 2015;10(4):e0122899.

21. Chou C-I, Shih C-J, Chen Y-T, et al. Adverse effects of oral nonselective and cyclooxygenase-2-selective NSAIDs on hospitalization for acute kidney injury: a nested case-control cohort study. Medicine. 2016;95(9):e2645.
22. Chang Y-K, Liu J-S, Hsu Y-H, Tarng D-C, Hsu C-C. Increased risk of end-stage renal disease (ESRD) requiring chronic dialysis is associated with use of nonsteroidal anti-inflammatory drugs (NSAIDs): nationwide case-crossover study. Medicine. 2015;94(38):e1362.

23. Tomlin AM, Reith DM, Woods DJ, et al. A pharmacoepidemiology database system for monitoring risk due to the use of medicines by New Zealand primary care patients. Drug Saf. 2017;40(12): 1259-77.

24. Bouck Z, Mecredy GC, Ivers NM, et al. Frequency and associations of prescription nonsteroidal antiinflammatory drug use among patients with a musculoskeletal disorder and hypertension, heart failure, or chronic kidney disease. JAMA Intern Med. 2018;178(11):1516-25.

25. Ministry of Education, Culture, Sports, Science and Technology Japan and Ministry of Health, Labour and Welfare Japan. Ethical guidelines for medical and health research involving human subjects. 2018. https://www.lifescience.mext.go.jp/files/pdf/ n2181_01.pdf. Accessed Dec 2020.

26. Imai E, Horio M, Watanabe $\mathrm{T}$, et al. Prevalence of chronic kidney disease in the Japanese general population. Clin Exp Nephrol. 2009;13(6):621-30.

27. Loos-Ayav C, Briançon S, Frimat L, André J, Kessler $\mathrm{M}$. Incidence of chronic kidney disease in general population, EPIRAN study. Nephrol Ther. 2009;5(Suppl 4):S250-5.

28. Dreischulte T, Morales DR, Bell S, Guthrie B. Combined use of nonsteroidal anti-inflammatory drugs with diuretics and/or renin-angiotensin system inhibitors in the community increases the risk of acute kidney injury. Kidney Int. 2015;88(2): 396-403.

29. Leonard CE, Freeman CP, Newcomb CW, et al. Proton pump inhibitors and traditional nonsteroidal anti-inflammatory drugs and the risk of acute interstitial nephritis and acute kidney injury. Pharmacoepidemiol Drug Saf. 2012;21(11): 1155-72.

30. Collins AJ, Vassalotti JA, Wang C, et al. Who should be targeted for CKD screening? Impact of diabetes, hypertension, and cardiovascular disease. Am J Kidney Dis. 2009;53(Suppl 3):S71-7.

31. Weinstein JR, Anderson S. The aging kidney: physiological changes. Adv Chronic Kidney Dis. 2010;17(4):302-7.

32. Hörl WH. Nonsteroidal anti-inflammatory drugs and the kidney. Pharmaceuticals. 2010;3(7): 2291-321. 
33. Lapi F, Azoulay L, Yin H, Nessim SJ, Suissa S. Concurrent use of diuretics, angiotensin converting enzyme inhibitors, and angiotensin receptor blockers with non-steroidal anti-inflammatory drugs and risk of acute kidney injury: nested casecontrol study. BMJ. 2013;346:e8525.

34. Adhiyaman V, Asghar M, Oke A, White AD, Shah IU. Nephrotoxicity in the elderly due to co-prescription of angiotensin converting enzyme inhibitors and nonsteroidal anti-inflammatory drugs. J R Soc Med. 2001;94(10):512-4.

35. Zhai X-J, Yu Y, Chen F, Lu Y-N. Comparative bioavailability and tolerability of single and multiple doses of 2 diclofenac sodium sustained-release tablet formulations in fasting, healthy Chinese male volunteers. Curr Ther Res Clin Exp. 2013;75: 53-8.

36. Yoakum PJ, Kasen J, Hindahl SL, Herndon C. Topical nonsteroidal anti-inflammatory drugs and nephrotoxicity: is there a safer option? practical pain management 2017; Article 10. https://www. practicalpainmanagement.com/treatments/topicalnonsteroidal-anti-inflammatory-drugsnephrotoxicity-there-safer-option. Accessed May 2020.

37. Umemura S, Arima H, Arima S, et al. The Japanese Society of Hypertension guidelines for the management of hypertension (JSH 2019). Hypertens Res. 2019;42(9):1235-481.

38. Murray MD, Brater DC, Tierney WM, Hui SL, McDonald CJ. Ibuprofen-associated renal impairment in a large general internal medicine practice. Am J Med Sci. 1990;299(4):222-9.

39. Nitta K, Norrio H, Shunsuke G, et al. 2018 Annual dialysis data report, JSDT renal data registry (in Japanese). Nihon Toseki Igakkai Zasshi. 2019;52(12):679-754.
40. Eknoyan G, Lameire N, Eckardt K, et al. KDIGO 2012 clinical practice guideline for the evaluation and management of chronic kidney disease. Kidney Int. 2013;3(1):5-14.

41. Patel K, Diamantidis C, Zhan M, et al. Influence of creatinine versus glomerular filtration rate on nonsteroidal anti-inflammatory drug prescriptions in chronic kidney disease. Am J Nephrol. 2012;36(1): 19-26.

42. Hull S, Mathur R, Dreyer G, Yaqoob MM. Evaluating ethnic differences in the prescription of NSAIDs for chronic kidney disease: a cross-sectional survey of patients in general practice. Br J Gen Pract. 2014;64(624):e448-55.

43. Adams RJ, Appleton SL, Gill TK, Taylor AW, Wilson DH, Hill CL. Cause for concern in the use of nonsteroidal anti-inflammatory medications in the community-a population-based study. BMC Fam Pract. 2011;12(70):1-80.

44. Zhang X, Donnan PT, Bell S, Guthrie B. Non-steroidal anti-inflammatory drug induced acute kidney injury in the community dwelling general population and people with chronic kidney disease: systematic review and meta-analysis. BMC Nephrol. 2017;18(1):256.

45. Takura T, Nakanishi T, Kawanishi H, et al. Costeffectiveness of maintenance hemodialysis in Japan. Ther Apher Dial. 2015;19(5):441-9.

46. Li PKT, Lui SL, Ng JKC, et al. Addressing the burden of dialysis around the world: a summary of the roundtable discussion on dialysis economics at the first International congress of Chinese nephrologists 2015. Nephrology. 2017;22(suppl 4):3-8.

47. Cohen LM, Germain MJ. Caregiver burden and hemodialysis. Clin J Am Soc Nephrol. 2014;9(5): 840-2. 